\title{
Development
}

\section{Homeostatic Recovery of Embryonic Spinal Activity Initiated by Compensatory Changes in Resting Membrane Potential}

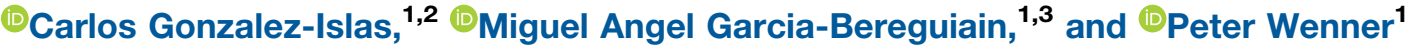

https://doi.org/10.1523/ENEURO.0526-19.2020

${ }^{1}$ Physiology Department, Emory University, School of Medicine, Atlanta, GA 30322, '2Doctorado en Ciencias Biológicas, Univerisdad Autónoma de Tlaxcala, Tlaxcala 90070, Mexico, and ${ }^{3}$ One Health Research Group, Universidad de Las Americas, Quito 170505, Ecuador

\begin{abstract}
When baseline activity in a neuronal network is modified by external challenges, a set of mechanisms is prompted to homeostatically restore activity levels. These homeostatic mechanisms are thought to be profoundly important in the maturation of the network. It has been shown that blockade of either excitatory GABAergic or glutamatergic transmission in the living chick embryo transiently blocks the movements generated by spontaneous network activity (SNA) in the spinal cord. However, the embryonic movements then begin to recover by $2 \mathrm{~h}$ and are completely restored by $12 \mathrm{~h}$ of persistent receptor blockade. It remains unclear what mechanisms mediate this early recovery (first hours) after neurotransmitter blockade, or even if the same mechanisms are triggered following GABAergic and glutamatergic antagonists. Here we find two distinct mechanisms that could underlie this homeostatic recovery. First, we see a highly robust compensatory mechanism observed shortly after neurotransmitter receptor blockade. In the first $2 \mathrm{~h}$ of GABAergic or glutamatergic blockade in vitro, there was a clear depolarization of resting membrane potential (RMP) in both motoneurons and interneurons. These changes reduced threshold current and were observed in the continued presence of the antagonist. Therefore, it appears that fast changes in RMP represent a key fast homeostatic mechanism for the maintenance of network activity. Second, we see a less consistent compensatory change in the absolute threshold voltage in the first several hours of in vitro and in vivo neurotransmitter blockade. These mechanisms likely contribute to the homeostatic recovery of embryonic movements following neurotransmitter blockade.
\end{abstract}

Key words: homeostatic; intrinsic plasticity; Na K ATPase; resting membrane potential; synpatic scaling; threshold voltage

\section{Significance Statement}

Homeostatic plasticity represents a set of mechanisms that act to recover cellular or network activity following a challenge and is thought to be critical for the developmental construction of the nervous system. The chick embryo afforded us the opportunity to observe the timing of homeostatic recovery of network activity following two distinct perturbations in a living developing system. Because of this advantage, we have identified a novel homeostatic mechanism that actually occurs as the network recovers and is therefore likely to contribute to nervous system homeostasis. We found that a depolarization of the resting membrane potential (RMP) and a hyperpolarization of threshold voltage in the first hours of the perturbation enhances excitability and supports the recovery of embryonic spinal network activity.

Received December 14, 2019; accepted May 22, 2020; First published June 15, 2020.

The authors declare no competing financial interests.
Author contributions: C.G.-I. and P.W. designed research; C.G.-I. and M.A.G.-B. performed research; C.G.-I., M.A.G.-B., and P.W. analyzed data; C.G.-I., M.A.G.-B., and P.W. wrote the paper. 


\section{Introduction}

Recent work has focused on the mechanisms that allow networks to homeostatically maintain their activity levels in the face of various perturbations (Marder and Goaillard, 2006; Turrigiano, 2011; Davis, 2013). Typically, activity is altered for $24 \mathrm{~h}$ or more and compensatory changes in intrinsic cellular excitability and/or synaptic strength (synaptic scaling) are observed following the perturbation. While most of the work has been conducted in vitro, homeostatic mechanisms have also been observed in vivo in the spinal cord (Gonzalez-Islas and Wenner, 2006; Knogler et al., 2010), hippocampal (Echegoyen et al., 2007), auditory (Kuba et al., 2010), and visual systems (Desai et al., 2002; Goel et al., 2006). The chick embryo spinal cord expresses a spontaneously occurring network activity (SNA) that drives embryonic movements (O'Donovan, 1999; Blankenship and Feller, 2010). SNA likely occurs in all developing circuits shortly after synaptic connections form. In the embryonic spinal cord this activity is a consequence of the highly excitable nature of the nascent synaptic circuit where GABAergic neurotransmission is depolarizing and excitatory during early development (Ben-Ari et al., 1989; O’Donovan et al., 1998; O'Donovan, 1999; Rivera et al., 1999; Blankenship and Feller, 2010). Spinal SNA is known to be important in motoneuron axonal pathfinding (Hanson and Landmesser, 2004), and for proper muscle and joint development (Ruano-Gil et al., 1978; Toutant et al., 1979; Roufa and Martonosi, 1981; Persson, 1983; Hall and Herring, 1990; Jarvis et al., 1996).

The embryonic spinal cord provides an exceptional model of homeostasis. Many years ago, it was demonstrated that SNA expressed in the isolated spinal cord was transiently blocked by either glutamatergic or $\mathrm{GABA}_{\mathrm{A}}$ receptor $\left(G A B A_{A} R\right)$ antagonists, but within hours was homeostatically restored in the presence of that antagonist (Barry and O'Donovan, 1987; Chub and O'Donovan, 1998). However, the mechanisms of this recovery have not been identified. Interestingly, a similar homeostatic recovery of SNA-generated embryonic movements following neurotransmitter antagonists has also been demonstrated in vivo (Wilhelm and Wenner, 2008). When $\mathrm{GABA}_{\mathrm{A}}$ or glutamate receptor antagonists were injected into the egg at embryonic day 8 (E8), SNA-driven embryonic movements were abolished for 1-2 $\mathrm{h}$ but then homeostatically recovered to control levels $12 \mathrm{~h}$ after the onset of pharmacological blockade of either transmitter (Wilhelm and Wenner, 2008). Therefore, it would be expected that mechanisms that contribute to the homeostasis of activity in the living system

This work was supported by the National Institute of Neurological Disorders and Stroke Grant R01NS065992 (to P.W.). MAGB was recipient of a fellowship from INEDITA (SENESCYT), Ecuador.

Acknowledgements: We thank Dr. Mark Rich and Dr. Morten Raastad for their valuable comments on this manuscript. Experiments were performed at Emory University.

Correspondence should be addressed to Peter Wenner at pwenner@ emory.edu.

https://doi.org/10.1523/ENEURO.0526-19.2020

Copyright (C) 2020 Gonzalez-lslas et al.

This is an open-access article distributed under the terms of the Creative Commons Attribution 4.0 International license, which permits unrestricted use, distribution and reproduction in any medium provided that the original work is properly attributed. will have occurred by $2-12 \mathrm{~h}$ of treatment. Because the recovery was very similar following either GABAergic or glutamatergic blockade, one might think that similar mechanisms would drive the recovery of embryonic activity following injection of either antagonist, but this did not appear to be the case. It was determined that following $12 \mathrm{~h}$ of GABAR blockade compensatory changes in intrinsic excitability were observed (increased $\mathrm{Na}^{+}$channel, and a decrease of two different $\mathrm{K}^{+}$channel currents, $\mathrm{I}_{\mathrm{A}}$ and $\mathrm{I}_{\mathrm{Ca}}$ ), although changes in quantal amplitude were not observed until $48 \mathrm{~h}$ of receptor blockade (Wilhelm and Wenner, 2008; Wilhelm et al., 2009). On the other hand, following a 12-h glutamatergic blockade, no changes in intrinsic excitability were observed, and after $48 \mathrm{~h}$ of glutamatergic blockade, no change in quantal amplitude was seen.

Previous studies had not examined the possibility that compensatory changes in cell excitability and/or scaling were occurring at the onset and throughout the recovery process in motoneurons. In fact, very few studies have compared the expression of presumptive homeostatic mechanisms with the timing of the homeostatic recovery of activity, yet we would expect that some of these mechanisms would be expressed at the very onset of the recovery process. Further, there is little known about compensations that may be occurring in the interneurons that contribute to the drive of SNA. Therefore, we set out to identify the mechanisms that are expressed during the actual period of homeostatic recovery of SNA. We found some changes in threshold voltage, but importantly we describe a previously unrecognized mechanism of homeostatic intrinsic plasticity where fast changes in resting membrane potential (RMP) bring both interneurons and motoneurons closer to action potential threshold. The results suggest that compensatory changes in RMP could facilitate the homeostatic recovery of activity during glutamatergic or GABAergic blockade in the living embryo.

\section{Materials and Methods}

\section{Dissection}

E10 (or stage 36; Hamburger and Hamilton, 1951) chick spinal cords were dissected under cooled $\left(15^{\circ} \mathrm{C}\right)$ Tyrode's solution containing the following: $139 \mathrm{~mm} \mathrm{NaCl}, 12 \mathrm{~mm}$ Dglucose, $17 \mathrm{~mm} \mathrm{NaHCO} 3,3 \mathrm{~mm} \mathrm{KCl,} 1 \mathrm{~mm} \mathrm{MgCl}$, and 3 $\mathrm{mM} \mathrm{CaCl} 2$; constantly bubbled with a mixture of $95 \% \mathrm{O}_{2}-$ $5 \% \mathrm{CO}_{2}$ to maintain oxygenation and $\mathrm{pH}$ around 7.3. After the dissection, the cord was allowed to recover overnight in Tyrode's solution at $18^{\circ} \mathrm{C}$. The next day, the cord was transferred to a recording chamber and continuously perfused with Tyrode's solution heated to $27^{\circ} \mathrm{C}$ to allow for the expression of bouts of SNA with a consistent frequency.

\section{Electrophysiology}

Whole-cell current clamp recordings were made from spinal motoneurons localized in lumbosacral segments 1-3 and were identified by their lateral position in the ventral cord. Recordings were also made from interneurons in the same segments, but these were identified by their more medial position in the ventral cord. Patch clamp tight seals (1-3 G $\Omega$ ) were obtained using 

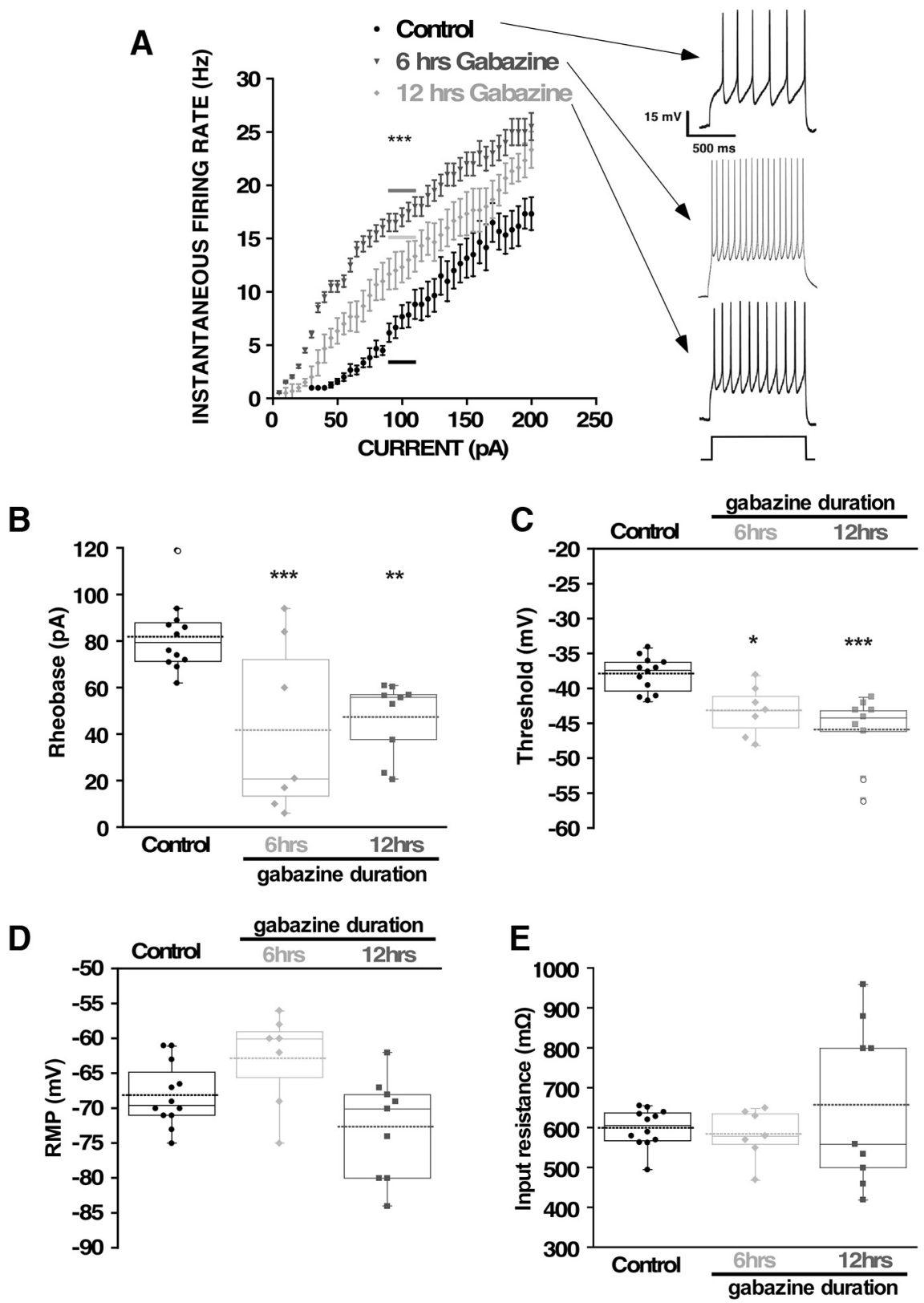

Figure 1. Changes in motoneuron excitability observed after chronic in vivo gabazine treatments. Motoneuron excitability was measured in isolated embryonic spinal cords by whole-cell current clamp using progressively more depolarized current steps to assess rheobase current and voltage threshold. Measurements were obtained from embryos that were untreated (12 cells, five cords), or treated for $6 \mathrm{~h}$ (seven cells, four cords) or $12 \mathrm{~h}$ (nine cells, five cords) with gabazine (10 $\mu \mathrm{M}$ at E9.5 or E9.75). A, Average F-I curves for control motoneurons $(n=9)$, 6-h gabazine treatment $(n=6)$ or 12 -h gabazine treatment $(n=9)$. Gabazine treatments shifted the average F-I curve to the left. All curves were significantly different from each other (values for steps of 90-110 pA were combined, horizontal bar, one-way ANOVA, Tukey's post hoc test $p<0.001)$. The arrows point to representative traces for each condition evoked by current steps of $100 \mathrm{pA}$. Threshold current $(\boldsymbol{B})$ or threshold voltage $(\boldsymbol{C})$ was obtained by determining the minimum current necessary to evoke a spike in the recorded motoneuron. No significant changes in RMP $(\boldsymbol{D})$ or input resistance $(\boldsymbol{E})$ were found in the motoneurons recorded after chronic gabazine treatment at 6 or $12 \mathrm{~h} ; * p<0.05, * * p<0.01, * * * p<0.001$.

electrodes pulled from thin-walled borosilicate glass (World Precision Instruments, Inc) in two stages, using a P-87 Flaming/Brown micropipette puller (Sutter Instruments) to obtain resistances between 5 and 10 $\mathrm{M} \Omega$. Once whole-cell configuration was achieved, voltage clamp at $-70 \mathrm{mV}$ was maintained for a period of 5 min to allow stabilization before switching to current clamp configuration at which point the RMP was measured. A liquid junction potential of $-12 \mathrm{mV}$ was experimentally measured (Neher, 1992) for our conditions. All reported RMP and threshold values were then corrected offline. In some cases, whole-cell voltage clamp recordings were also obtained from motoneurons and interneurons to acquire miniature postsynaptic currents 
Table 1: Cellular excitability measures for motoneurons and interneurons following different treatments in vitro and in vivo

\begin{tabular}{|c|c|c|c|c|c|c|c|c|}
\hline & Motoneuron & Motoneuron & & & Interneuron & Interneuron & Interneuron & Interneuron \\
\hline Controls in vivo & $81.8 \pm 4.3$ & $30.3 \pm 1.6$ & $-68.1 \pm 1.3$ & $599.6 \pm 13.8$ & $84.1 \pm 8.3$ & $34.7 \pm 2.7$ & $-70.2 \pm 2.2$ & $578.5 \pm 49.0$ \\
\hline $\begin{array}{c}\text { GABA }_{A} R \text { blockers } \\
12 \mathrm{~h} \text { in vivo }\end{array}$ & $47.3 \pm 5.3$ & $26.8 \pm 2.9$ & $-72.7 \pm 2.4$ & $657.2 \pm 67.3$ & $20.6 \pm 3.7$ & $21.1 \pm 2.3$ & $-66.0 \pm 2.2$ & $624.8 \pm 88.1$ \\
\hline $\begin{array}{c}\mathrm{GABA}_{\mathrm{A}} \mathrm{R} \text { blockers } \\
2-4 \mathrm{~h} \text { in vitro }\end{array}$ & $21.8 \pm 7.2$ & $28.1 \pm 1.8$ & $-58.6 \pm 1.8$ & $474.4 \pm 22.0$ & $35.7 \pm 7.4$ & $21.6 \pm 1.4$ & $-55.4 \pm 1.3$ & $550.56 \pm 70.0$ \\
\hline $\begin{array}{c}\mathrm{GABA}_{\mathrm{A}} \mathrm{R} \text { blockers } \\
4-6 \mathrm{~h} \text { in vitro }\end{array}$ & $32.1 \pm 6.3$ & $20.0 \pm 1.4$ & $-60.3 \pm 1.1$ & $442.0 \pm 41.0$ & $16.5 \pm 2.5$ & $15.8 \pm 1.5$ & $-60.3 \pm 1.5$ & $582.5 \pm 109.13$ \\
\hline $\begin{array}{l}\text { GluR blockers } \\
0-2 \mathrm{~h} \text { in vitro }\end{array}$ & $46.6 \pm 10.3$ & $18.6 \pm 7.2$ & $-57.4 \pm 1.5$ & $492.7 \pm 76.1$ & $34.3 \pm 8.7$ & $15.8 \pm 1.1$ & $-55.4 \pm 1.1$ & $555.9 \pm 56.4$ \\
\hline
\end{tabular}

Numbers in bold are show significant difference with controls. Measures are averages \pm SEs.

(mPSCs), and these recordings were obtained for the first 5-10 min of the recording before switching to current clamp to record measures of excitability. Series resistance during the recording varied from 15 to $20 \mathrm{M} \Omega$ among different neurons and was not compensated. Voltage clamp recordings were terminated whenever significant increases in series resistance $(>20 \%)$ occurred or when holding current became larger than $50 \mathrm{pA}$. Cell capacitance was not compensated. Currents were filtered online at $5 \mathrm{kHz}$ and digitized at $10 \mathrm{kHz}$. AMPA and GABA mPSCs were separated by their decay kinetics as described previously (GonzalezIslas and Wenner, 2006). The mPSCs with decay time constants $(\tau)$ under $7 \mathrm{~ms}$ were counted as AMPAergic, and those with $\tau s$ over $10 \mathrm{~ms}$ were counted as GABAergic (Gonzalez-Islas and Wenner, 2006). We did not add tetrodotoxin (TTX) to isolate mPSCs in this study because the frequency and amplitude of spontaneous events (no TTX) and mPSCs in the presence of TTX have been shown to be the same (Chub and O'Donovan, 2001; Gonzalez-Islas and Wenner, 2006). The mPSCs were acquired on an Axopatch 200B patch clamp amplifier (Molecular Devices), digitized (Digidata 1200, Molecular Devices) on-line using PClamp 10 (Molecular Devices), and analyzed manually using Minianalysis software (Synaptosoft). For these recordings, if peak to peak noise was larger than $5 \mathrm{pA}$ or the RMS was larger than $1 \mathrm{pA}$, then the recording was not included in the analysis. The mPSCs were identified automatically by Minianalysis using the following parameters: threshold, $5 \mathrm{pA}$; period to search a local maximum, $50 \mathrm{~ms}$; time before a peak for baseline, $10 \mathrm{~ms}$; period to search for a decay time, $35 \mathrm{~ms}$; fraction of peak to find a decay time, 0.37 period to average a baseline $5 \mathrm{~ms}$; area threshold 10 ; number of point to average peak 7 ; direction of peak; negative. We then went through these miniwaveforms and accepted them or rejected them following visual inspection of the waveform. Charts and associated average values were obtained by determining an average mPSC amplitude for each cell (variable number of mPSCs/cell, 5-pA cutoff), and then calculating the average of all cells. Recordings in current clamp were terminated whenever significant increases in input resistance $(>20 \%)$ occurred. Current clamp recordings were filtered online at $10 \mathrm{kHz}$, digitized at $20 \mathrm{kHz}$. The intracellular patch solution for both current and voltage clamp recordings contained the following: $5 \mathrm{~mm} \mathrm{NaCl}, 100 \mathrm{~mm} \mathrm{~K}$-gluconate, $36 \mathrm{~mm} \mathrm{KCl}, 10$ mм HEPES, $1.1 \mathrm{~mm}$ EGTA, $1 \mathrm{~mm} \mathrm{MgCl}_{2}$, $0.1 \mathrm{~mm} \mathrm{CaCl}_{2}, 1$ $\mathrm{mm} \mathrm{Na} \mathrm{N}_{2} \mathrm{ATP}$, and $0.1 \mathrm{~mm}$ MgGTP; pipette solution osmolarity was between 280 and $300 \mathrm{mOsm}$, and pH was adjusted to 7.3 with $\mathrm{KOH}$. Standard extracellular recording solution was Tyrode's solution (see above), constantly bubbled with a mixture of $95 \% \mathrm{O}_{2}-5 \% \mathrm{CO}_{2}$. In order to obtain rheobase, threshold voltage, and F-I relationships in embryos treated with saline or gabazine in ovo, a step protocol was employed (1-s duration, 1-pA increments for threshold/rheobase or 5-pA increments for the FI curve, at $0.1 \mathrm{~Hz}$ ). To expedite this process so we could obtain more accurately timed measures of rheobase and threshold voltage following in vitro application of gabazine, a ramp protocol (from 0 to $200 \mathrm{pA} ; 1.2$-s duration at $0.2 \mathrm{~Hz}$; $n=3$ ) was used. A test pulse was delivered $800 \mathrm{~ms}$ before every step pulse or ramp, a 200-ms hyperpolarizing current step of $20 \mathrm{pA}$ was applied, and this provided our measure of input resistance and also served as an indicator of the reliability of the step. The RMP values were taken as an average of the $V_{m}$ read at the beginning of each sweep in these protocols. Although most of the experiments were not blinded, in four experiments, the drug application in ovo was done blindly to corroborate the results.

\section{In ovo and in vitro drug injections}

A window in the shell of the egg was opened to allow monitoring of chick embryo movements and drug 
A

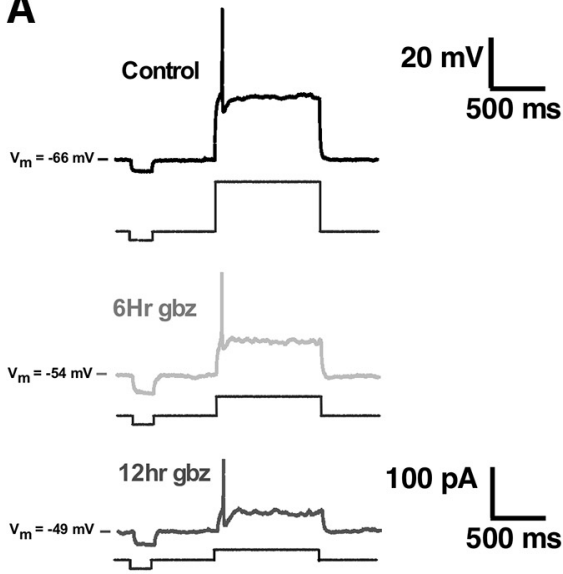

C

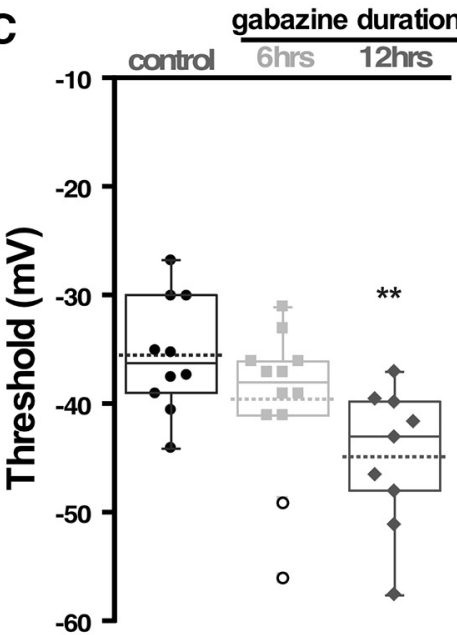

B

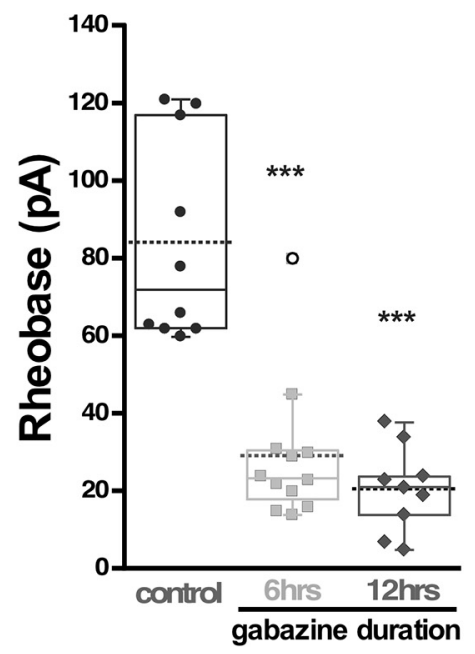

D

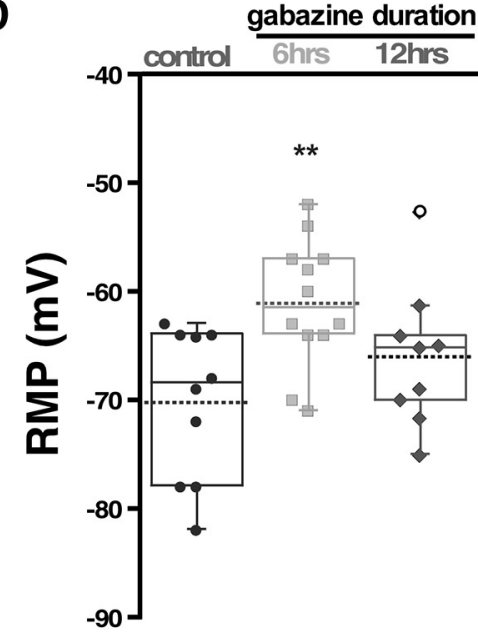

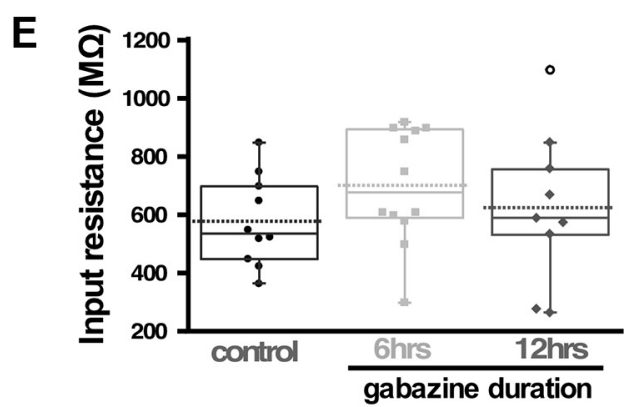

Figure 2. Interneuron excitability increased following in vivo GABAergic blockade. $\boldsymbol{A}$, Interneuron excitability was measured in isolated spinal cords from control or after in ovo chronic treatment with gabazine (10 $\mu \mathrm{m})$ for 6 or $12 \mathrm{~h}$. A step protocol (1 s, in 1-pA increments) was used to assess rheobase current and voltage threshold. Representative traces of interneuron firing in control (10 cells, five cords), or after $6 \mathrm{~h}$ (12 cells, four cords) and $12 \mathrm{~h}$ ( $n=9$, three cords) of chronic in ovo treatment with gabazine. Under each trace, the corresponding rheobase current applied to evoke firing is shown. RMP is also indicated at the left of each trace. Box and whisker plots superimposed to their corresponding dot plots show quartile distribution and individual values for Rheobase (B), spike threshold voltage $(\boldsymbol{C}), \mathrm{RMP}(\boldsymbol{D})$, and input resistance $(\boldsymbol{E})$. Kruskal-Wallis method followed by a post hoc Dunn test was used to assess statistical significance; $* * p<0.01$ and $* * * p<0.001$. For all plots, the continuous line represents the median and the dotted line represent the mean of the sample.

application 6 or $12 \mathrm{~h}$ before isolating the spinal cord at E10. A total of $50 \mu \mathrm{l}$ of a $10 \mathrm{~mm}$ gabazine solution was applied onto the chorioallantoic membrane of the chick embryo to a final concentration of $\sim 10 \mu \mathrm{m}$, assuming a $50-\mathrm{ml}$ egg volume. For the in vitro drug application, 10 $\mu \mathrm{M}$ gabazine or $20 \mu \mathrm{M}$ 6-cyano-7-nitroquinoxaline-2,3dione disodium (CNQX) and $50 \mu \mathrm{M}$ D-(-)-2-amino-5phosphonopentanoic acid (APV) was added to the perfusate after recording from untreated/control neurons for the first $2-3 \mathrm{~h}$. 


\section{Recording of SNA}

For monitoring SNA, tight-fitting glass suction electrodes were used to record ventrolateral funiculus (VLF) signals as described previously (O'Donovan and Landmesser, 1987). VLF signals were amplified $(1000 \times)$, filtered $(0.1 \mathrm{~Hz}$ to $1 \mathrm{kHz}$ ) by an extracellular amplifier (A-M Systems Inc.), and acquired using PClamp 10 (Molecular Devices). Analyses of the data were performed offline.

\section{Immunoblots}

The ventral half of the lumbosacral spinal cords were homogenized in RIPA buffer containing protease and phosphatase inhibitors. Samples were then centrifuged to remove cell debris. Protein concentration was quantitated using BCA reagent (Pierce). Samples were separated on 4$15 \%$ SDS-PAGE and blotted to a nitrocellulose membrane. Films were scanned and analyzed using free software, ImageJ, with background correction and normalization to actin. The primary antibodies against Nav1.2 and Kv4.2 were from Alomone Labs. The blots were visualized by ECL chemiluminescence (GE Healthcare). Lysate from the ventral half of four different cords/chicks per treatment were used and blots were done in duplicate (total eight embryos per treatment).

\section{Drugs}

SR-95531 hydrobromide (gabazine), CNQX, APV, and dihydro- $\beta$-erythroidine hydrobromide $(\mathrm{DH} \beta \mathrm{E})$ were purchased from Tocris Cookson (catalog numbers 1262, 1045,0106 , and 2349, respectively). All other chemicals and drugs were purchased from Sigma-Aldrich.

\section{Statistics}

Data are expressed as mean \pm SE. Statistical analysis of cellular excitability parameters was performed using ANOVA followed by Bonferroni post hoc test for multiple comparisons for normally distributed data and KruskalWallis method followed by a post hoc Dunn test for data that was not normally distributed, unless mentioned otherwise. For statistical assessment of mPSC amplitude, we used a Student's $t$ test for normally distributed data, and Mann-Whitney test for data that was not normally distributed. For all of the experiments, the number of cells and cords are indicated in parenthesis at the bottom of the corresponding figure legend. Throughout the manuscript, $* p \leq 0.05, * * p \leq 0.01$, and $* * * p \leq 0.001$.

\section{Results}

\section{Changes in spinal neuron excitability in the first $12 \mathrm{~h}$ of in vivo GABAergic blockade}

Previous work showed that spinal motoneuron voltagegated $\mathrm{Na}^{+}$and $\mathrm{K}^{+}$channel currents were altered following $12 \mathrm{~h}$ of in ovo GABAergic blockade, after embryonic movements had homeostatically recovered (Wilhelm et al., 2009). In order to determine whether these changes actually contribute to the recovery, we assessed cellular excitability in motoneurons during the period that the SNA-driven movements were actually recovering, but before complete recovery was achieved. First, we tested

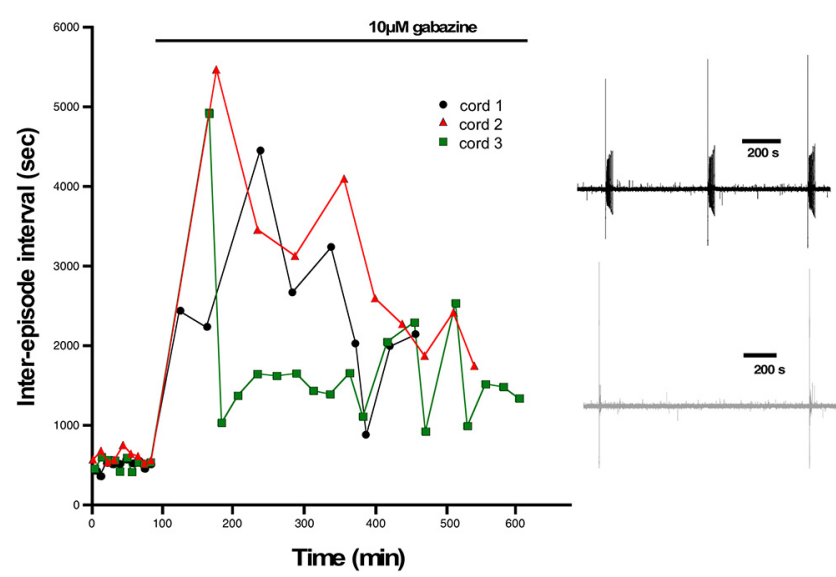

Figure 3. Episodes of SNA are abolished and then begin to recover following GABAergic blockade. The interval between episodes of SNA are plotted against elapsed time for three different cords before and following addition of gabazine to the bath. Episode intervals were increased following GABAergic block (10 $\mu \mathrm{m}$ gabazine), but then began to recover in the hours following gabazine. Inset shows example traces of SNA from a cord before (black) and after bath addition of gabazine (gray). Traces were filtered from $0.1 \mathrm{~Hz}$ to $10 \mathrm{kHz}$.

whether cellular excitability had increased during the period that movements were in the process of homeostatically recovering, following $6 \mathrm{~h}$ of gabazine treatment (10 $\mu \mathrm{M})$ in ovo. We isolated the spinal cord following saline/ gabazine treatment and recorded whole cell in current clamp from motoneurons that were no longer in the presence of gabazine. We found that threshold current (rheobase) was reduced and the absolute threshold voltage was hyperpolarized, suggesting the cells were more excitable following $6 \mathrm{~h}$ of gabazine treatment (Fig. 1B,C; Table 1). Following $12 \mathrm{~h}$ of gabazine treatment in ovo, similar changes were observed (Fig. 1B,C; Table 1). We also assessed excitability by giving current steps and plotting this against firing frequency after either 6 or $12 \mathrm{~h}$ of gabazine treatment (Fig. $1 A$ ). We saw a very strong shift toward higher excitability in the F-I curve at the 6-h time point, which then moved partly back toward predrug values following a 12-h treatment, although cells still showed a heightened excitability compared with controls. We did not observe changes in RMP or input resistance (Fig. 1D,E).

We wanted to determine whether these increases in cellular excitability were only occurring in motoneurons, or whether this was a more general phenomenon that extends to the rest of the developing motor circuitry. Thus, we assessed the possibility that spinal interneurons also increased cell excitability following gabazine treatment and could therefore contribute to the homeostatic recovery of SNA. Spinal neurons were targeted in the more medial positions of the cord. The population of spinal interneurons we recorded from were targeted blindly and therefore represent a diverse class of spinal interneurons with different neurotransmitters and activity patterns (Ritter et al., 1999). We found that, like motoneurons, interneurons had reduced threshold current at 6 and $12 \mathrm{~h}$ of gabazine treatment (Fig. 2B; Table 1). Threshold voltage 


\section{MOTONEURONS}

A

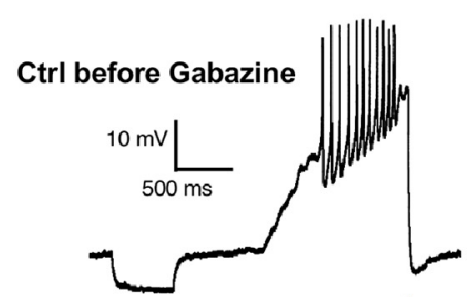

4 hrs Gabazine invitro
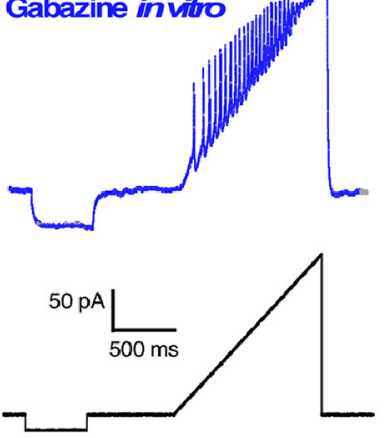

C

Control before Gabazine

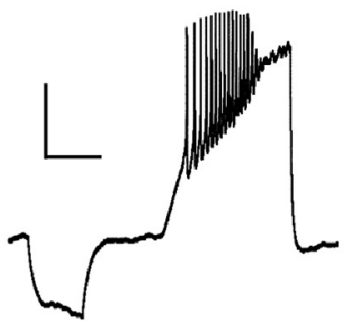

$4 \mathrm{hrs}$ Gabazine in vïtro

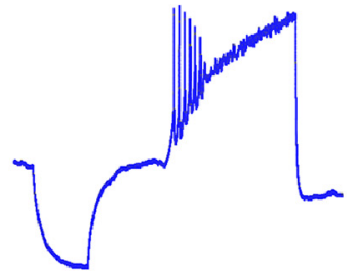

B1

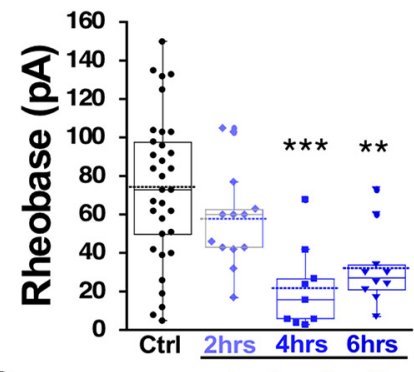

B3 gabazine duration

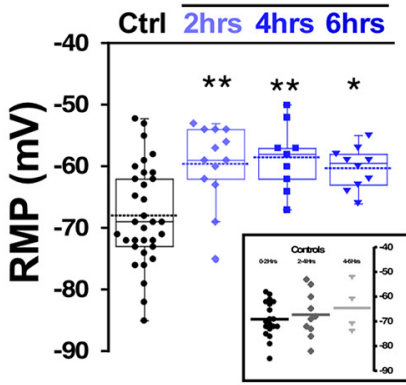

INTERNEURONS

D1

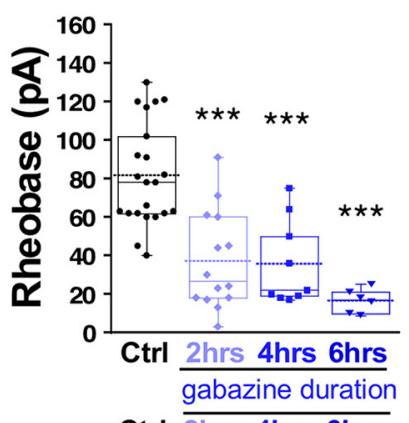

D3 Ctrl $\overline{2 \mathrm{hrs} 4 \mathrm{hrs} 6 \mathrm{hrs}}$

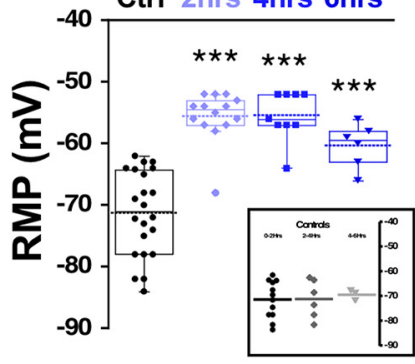

B2

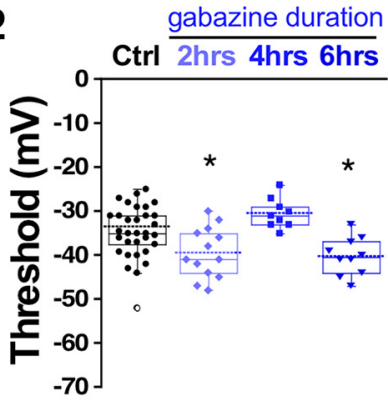

B4

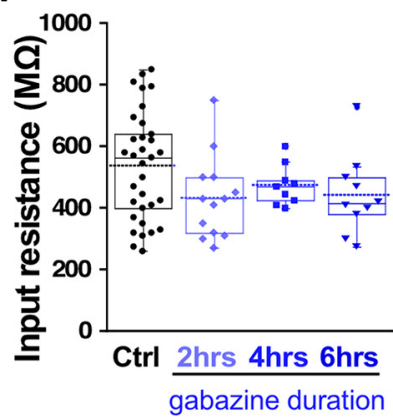

D2

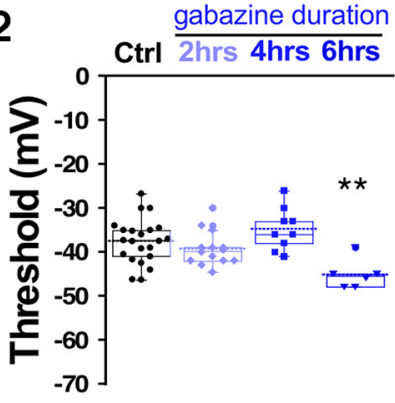

D4

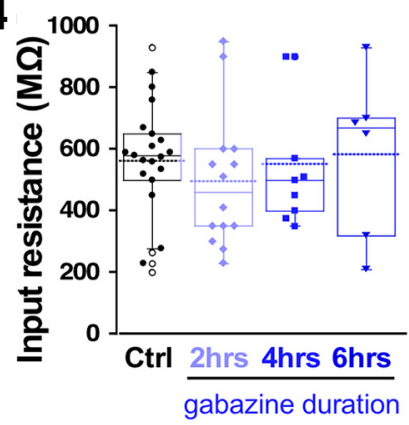

Figure 4. Spinal neuron excitability increased during the continuous blockade of GABARs in vitro. Motoneuron excitability was measured in isolated spinal cords using a ramp protocol from 0 to $200 \mathrm{pA}$ in $1.2 \mathrm{~s}$ to assess rheobase current and voltage threshold in the absence (control, 33 cells; 12 cords) or in the continuous presence of gabazine $10 \mu \mathrm{M}$ at three different blockade periods: 0-2 h (13 cells, four cords cells), 2-4 h (nine cells, three cords), and 4-6 h (10 cells, four cords). Representative traces of motoneuron firing in a control motoneuron or after $4 \mathrm{~h}$ in the continuous presence of gabazine in the bath. Lower trace shows the ramp protocol applied to evoke motoneuron firing $(\boldsymbol{A})$. Box and dot plots showing quartile distribution and individual values for of the rheobase (B1), threshold (B2), RMP (B3), and input resistance (B4) in control; 0-2, 2-4, and 4-6 h in gabazine. Inset of B3 shows results for cords that were never treated with gabazine, but cells were recorded in the first, second, or third 2-h periods. $\boldsymbol{C}, \boldsymbol{D}$, Interneuron excitability was measured in isolated spinal cords using the same protocol as above to assess rheobase and threshold in the absence (control, 22 cells; eight cords) or in the continuous presence of gabazine $(10 \mu \mathrm{M})$ at three different blockade periods: $0-2 \mathrm{~h}(14 \mathrm{cells}$, five cords), 2-4 h (nine cells, three cords), and 4-6 h (six cells, three cords). Representative traces of firing in a control interneuron 
continued

or after $4 \mathrm{~h}$ in the continuous presence of gabazine in the bath. Lower trace shows the ramp protocol applied to evoke interneuron firing $(\boldsymbol{C})$. Box and dot plots showing the value of the rheobase (D1), threshold (D2), RMP (D3), or input resistance (D4) in control; 0to 2-, 2- to 4-, and 4- to 6-h periods in the presence of gabazine. Inset of $\boldsymbol{D} 3$ shows results for cords that were never treated with gabazine but interneurons were recorded in the first, second or third 2-h period. Kruskal-Wallis method followed by a post hoc Dunn test was used to asses statistical significance; $* p<0.05, * * p<0.01, * * * p<0.001$. For all plots, the continuous line represents the median and the dotted line represent the mean of the sample.

was hyperpolarized at $12 \mathrm{~h}$ of gabazine treatment (Fig. $2 C$; Table 1). In addition, we did see a depolarization of the RMP at 6 h of treatment (Fig. 2D). Overall, the results suggest that there were increases in intrinsic excitability in motoneurons and interneurons at the point that embryonic movements were homeostatically recovering from in ovo GABAR blockade.

\section{Changes in spinal neuron excitability in the first $6 \mathrm{~h}$ of in vitro GABAergic blockade}

One advantage of the earlier experiments was that the perturbation was conducted in vivo. Unfortunately, to measure cellular excitability, the cord must be isolated, and was given several hours to recover in the absence of gabazine before we could make excitability measurements. Such a process could itself alter the excitability of the cells. Therefore, in addition to the in vivo perturbations, we wanted to assess cellular excitability changes in the isolated cord in vitro in the first $6 \mathrm{~h}$ after adding the GABAR antagonist gabazine $(10 \mu \mathrm{M})$. First, we added gabazine to the bath and observed its effect on the expression of SNA. Similar to previous work, we saw that episodes of SNA were initially blocked, but then began to recover in the following hours of GABAergic blockade (Fig. 3). As reported previously (Chub and O'Donovan, 1998), the duration of the episodes of SNA was reduced following bath addition of gabazine (Extended Data Fig. 31). To identify the mechanisms that recover SNA and which are expressed in the continued presence of gabazine we recorded whole cell in current clamp from motoneurons in the first (0-2), second (2-4), third (4-6) 2-h periods, and in cells that were never exposed to gabazine. Several aspects of cellular excitability were observed to increase in these first $6 \mathrm{~h}$ of GABAergic block. We saw a reduced threshold current (2-6 h; Fig. 4B1; Table 1), a hyperpolarized threshold voltage (0-2 and 4-6 h; Fig. 4B2; Table 1), and importantly, a fast $\sim 10 \mathrm{mV}$ depolarization of the RMP (0-6 h; Fig. 4B3; Table 1). Cords that were never treated with gabazine in vitro but where motoneurons were recorded from 0 to 2,2 to 4 , or 4 to $6 \mathrm{~h}$ after warming the bath showed that the depolarized RMP was not simply a time-dependent process (Fig. 4B3, inset). Interestingly, we did not see a significant change in input resistance (Fig. 4B4; Table 1). These results suggest that compensatory changes in motoneuron excitability occurs very quickly and therefore could contribute to the recovery of SNA. The most striking compensatory change was a depolarizing shift in the RMP.

Similar increases in cellular excitability were observed in interneurons from isolated cords that were treated with bath application of gabazine for $0-2,2-4$, and $4-6 \mathrm{~h}$ in vitro (Fig. 4D1-D4; Table 1). Cords that were never treated with gabazine but where interneurons were recorded from 0 to 2, 2 to 4 , or 4 to $6 \mathrm{~h}$ after warming the bath showed that the depolarized RMP was not simply a time-dependent process (Fig. 4D3, inset). Because we were recording from diverse classes of spinal neurons, the results suggest that various cell types alter their cellular intrinsic excitability and contribute to the recovery of activity following GABAergic blockade. Importantly, interneuron RMP was significantly depolarized at each of the time points (Fig. 4D3). No changes were observed in input resistance in any condition. Therefore, interneurons increased their cellular excitability after GABAergic blockade similarly to motoneurons.

Since the changes in cellular excitability following $\mathrm{GABA}_{\mathrm{A}} \mathrm{R}$ blockade appear to be expressed across multiple cell types throughout much of the cord, we ran Western blottings of isolated spinal cords (ventral half) and assessed 2 of the voltage-gated channels that we expected could mediate this process. It has been reported (Wilhelm et al., 2009) that gabazine-induced changes were observed in voltage-gated $\mathrm{Na}^{+}$and $\mathrm{K}^{+}$channels. In that study, we saw $\Pi$ TX-sensitive voltage-gated $\mathrm{Na}^{+}$channel currents were increased. Therefore, we assessed the levels of Nav1.2, an $\alpha$ subunit of the voltage-gated $\mathrm{Na}^{+}$channel, which had been shown to be expressed early in the development of the embryonic chick (Kuba et al., 2014). We found that following a 12-h gabazine treatment in ovo, Nav1.2 expression was increased $(172.4 \pm 14.8 \%, p \leq 0.05)$ but not after a 6 -h treatment (105.3 $\pm 5.3 \%$; Fig. 5). Further, it was also observed in that study that currents of the A-type transiently-activated $\mathrm{K}^{+}$channel $\left(\mathrm{I}_{\mathrm{A}}\right)$ and the calcium-

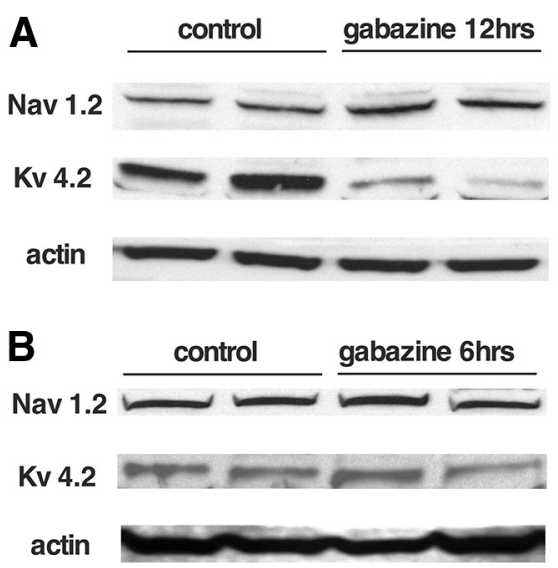

Figure 5. Changes in voltage-gated channel expression following in ovo gabazine treatment. Western blottings showing changes in the expression of voltage-dependent $\mathrm{Na}^{+}$channels (Nav1.2) and inactivating $\mathrm{K}^{+}$channels (Kv4.2) in the chick embryo spinal cord following $12 \mathrm{~h}(\boldsymbol{A})$ or $6 \mathrm{~h}(\boldsymbol{B})$ of GABAR blockade in ovo. 
A

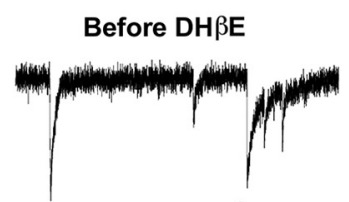

2 hrs in DHßE

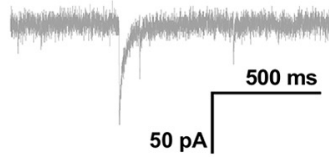

C

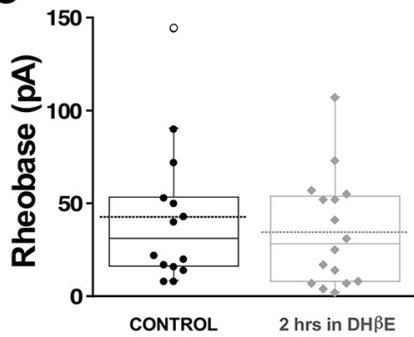

E

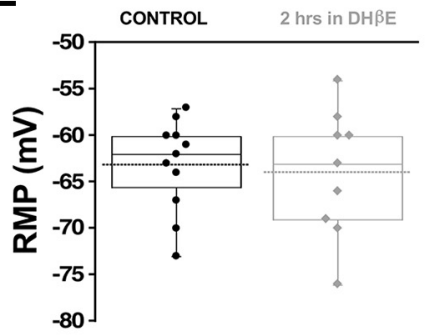

B

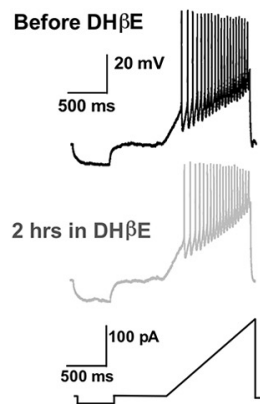

D

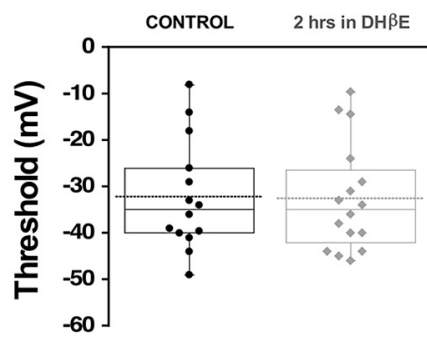

$\mathbf{F}$

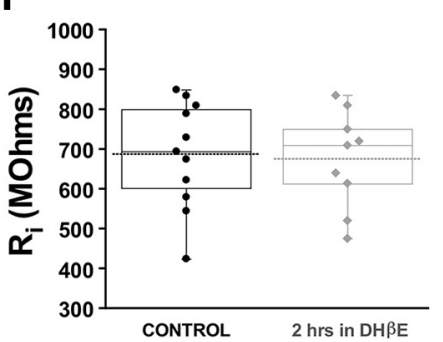

Figure 6. Chronic reductions in quantal GABA release that mediate synaptic upscaling do not trigger changes in motoneuron excitability. Whole-cell voltage and current clamp recordings from motoneurons were obtained from isolated spinal cords before (14 cells, six cords) or after $2 \mathrm{~h}$ of the nicotinic receptor antagonist (16 cells, six cords) $\mathrm{DH} \beta \mathrm{E}(10 \mu \mathrm{M})$. Representative traces are shown. Top black trace, $\mathrm{mPSC}$ before $\mathrm{DH} \beta \mathrm{E}$ addition; bottom gray trace, following nicotinic receptor inhibition with $\mathrm{DH} \beta \mathrm{E}$ addition (A). Despite this, no changes in intrinsic cell excitability were measured after $2 \mathrm{~h}$ of $\mathrm{DH} \beta \mathrm{E}$ treatment. Whole-cell current clamp recording during a ramp test showing representative traces of motoneurons, before and after $2 \mathrm{~h}$ of $\mathrm{DH} \beta \mathrm{E}(\boldsymbol{B})$. The ramp protocol was applied to evaluate rheobase current and voltage threshold. Box and dot plots show that rheobase (C) threshold $(\boldsymbol{D})$, RMP $(\boldsymbol{E})$, and input resistance $(\boldsymbol{F})$ were not different after $2 \mathrm{~h}$ of $\mathrm{DH} \beta \mathrm{E}$ compared with controls. A Mann-Whitney test was used to quantified statistical significance. For all plots, the continuous line represents the median and the dotted line represent the mean of the sample.

dependent $\mathrm{K}^{+}$channel $\left(\mathrm{lk}_{\mathrm{Ca}}\right)$ were both decreased following gabazine treatment (Wilhelm et al., 2009). Here, we show that expression of Kv4.2 (which mediates the A-type $\mathrm{K}^{+}$ channel in chick embryo; Dryer et al., 1998) is downregulated following a 12-h gabazine treatment $(54.5 \pm 2.5 \%$, $p \leq 0.05)$ but not after 6 h (104.2 $\pm 17.2 \%$; Fig. 5). Together, the results show that cellular excitability is altered during and after the homeostatic recovery of SNA and that expression changes in two different voltage-gated channels do not occur until later stages of the recovery.

\section{The trigger for changes in RMP was distinct from the homeostatic mechanisms expressed after GABAergic blockade}

Following $\mathrm{GABA}_{\mathrm{A}} \mathrm{R}$ blockade, compensatory changes in synaptic strength (scaling) were not observed until $48 \mathrm{~h}$, but voltage-gated conductance changes were triggered by $12 \mathrm{~h}$ (Wilhelm and Wenner, 2008; Wilhelm et al., 2009). It has been recently reported that simply reducing $\mathrm{GABA}_{A} \mathrm{R}$ activation due to spontaneous miniature release of GABA vesicles (spontaneous GABAergic transmission) was sufficient to trigger upscaling (Garcia-Bereguiain et al., 2016). We were able to do this by taking advantage of our observation that manipulating nicotinic receptor activation altered spontaneous GABAergic release (Gonzalez-Islas et al., 2016). In this previous study, we showed that the nicotinic antagonist $\mathrm{DH} \beta \mathrm{E}$ reduces $\mathrm{GABA}_{\mathrm{A}}$, but not AMPA, mPSCs by $\sim 30 \%$. Therefore, we tested the possibility that the fast changes in cellular excitability observed in the current study were also mediated by reduced spontaneous miniature GABAergic neurotransmission. Whole-cell recordings from motoneurons were obtained before and 2 $\mathrm{h}$ after $\mathrm{DH} \beta \mathrm{E}$ application in vitro. We did not find any 

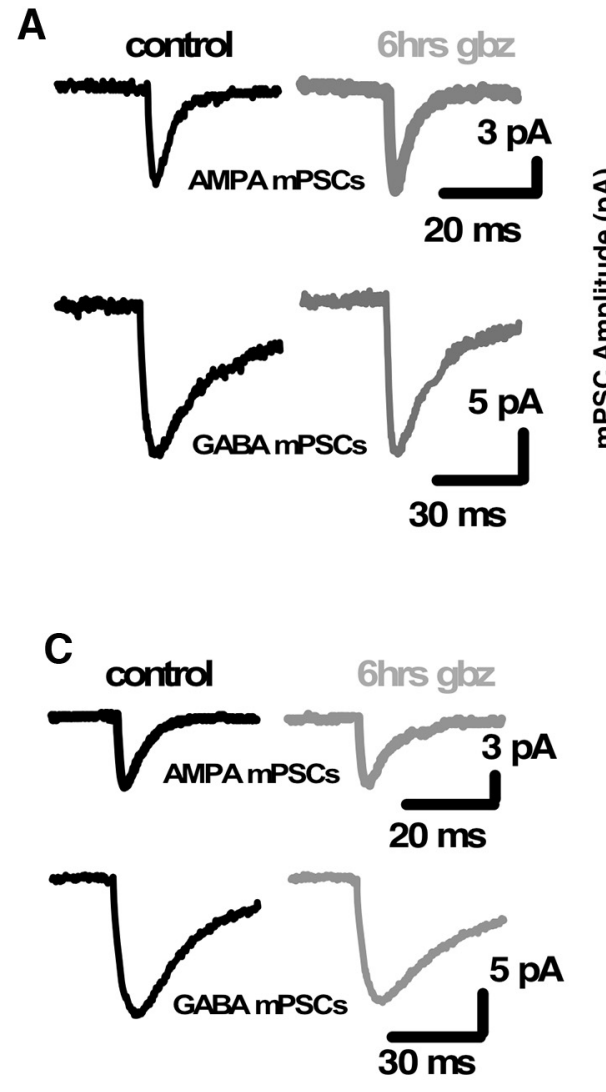

\section{INTERNEURONS}

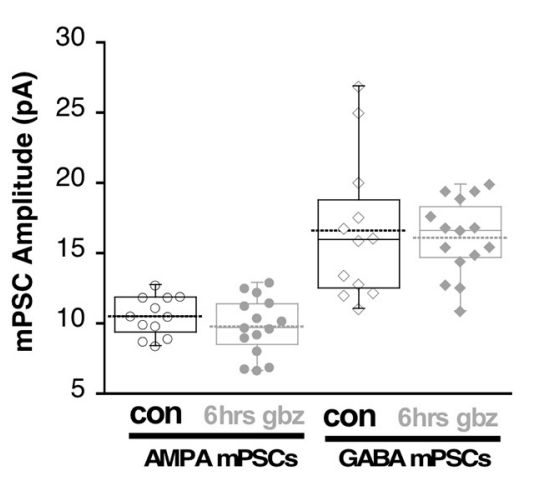

MOTONEURONS

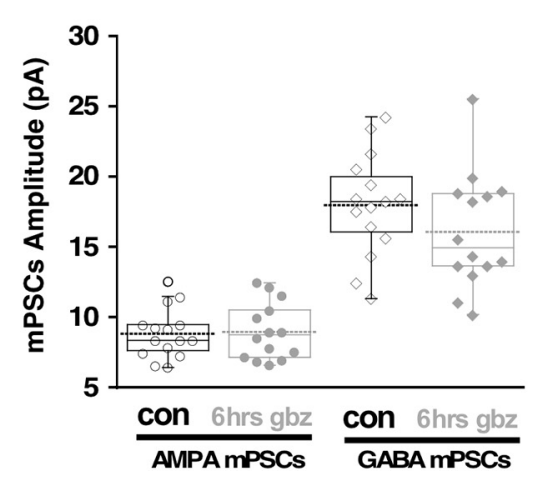

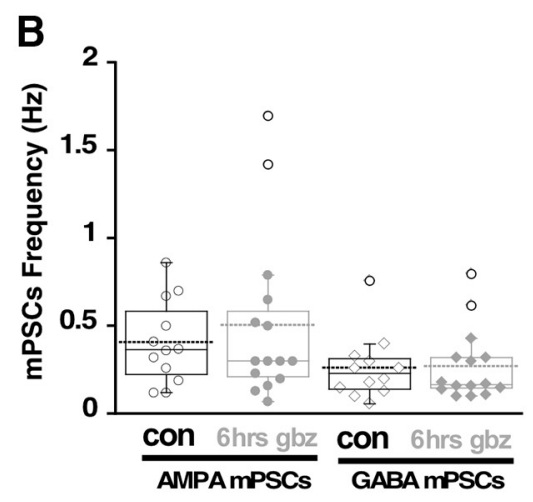

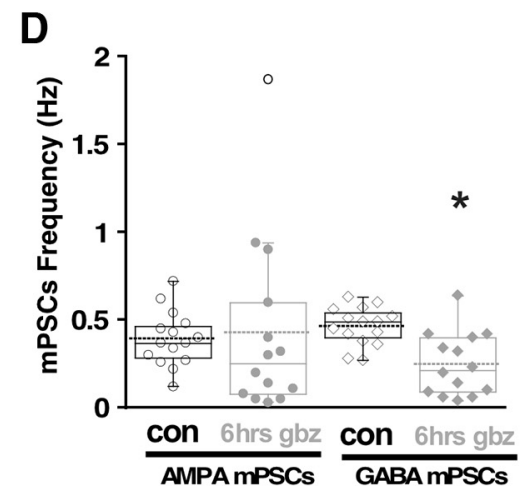

Figure 7. Synaptic scaling does not contribute to the homeostatic recovery of SNA-generated movements. $\boldsymbol{A}$, Representative traces of the average mPSCs from single interneurons in control conditions or after $6 \mathrm{~h}$ of in vivo gabazine treatment (left side). Box and dot plots (right side) showing quartile distribution and individual values for AMPAergic and GABAergic mPSC amplitudes from embryonic spinal interneurons in control conditions (12 cells, four cords) and after $6 \mathrm{~h}$ of chronic treatment with $10 \mu \mathrm{m}$ gabazine (15 cells, five cords). B, Box and dot plots showing AMPAergic and GABAergic mPSC frequency from embryonic spinal interneurons neurons in control conditions and after $6 \mathrm{~h}$ of chronic treatment with gabazine. $\boldsymbol{C}$, Representative traces of the average mPSCs from single motoneurons in control conditions or after $6 \mathrm{~h}$ of gabazine treatment (left side). Box and dot plots (right side) showing quartile distribution and individual values for AMPAergic and GABAergic mPSC amplitudes from embryonic spinal motoneurons in control conditions (15 cells, five cords) and after $6 \mathrm{~h}$ of chronic treatment with $10 \mu \mathrm{m}$ gabazine (14 cells, five cords). $\boldsymbol{D}$, Box and dot plots showing AMPAergic and GABAergic mPSC frequency from embryonic spinal motoneurons in control conditions and after $6 \mathrm{~h}$ of chronic treatment with gabazine. For all plots, the continuous line represents the median and the dotted line represent the mean of the sample. ${ }^{*} p<0.05$.

differences in cellular excitability following reduction of GABA quantal release by $\mathrm{DH} \beta \mathrm{E}$ (Fig. 6). Therefore, unlike the trigger for synaptic scaling, the compensatory changes in cellular excitability in the first hours of GABAergic blockade were not mediated by changes in spontaneous GABAergic transmission.

\section{Synaptic scaling does not contribute to the homeostatic recovery of SNA-generated movements}

Previously, it had been shown that AMPAergic and GABAergic upscaling were not observed in chick embryo motoneurons following a 12-h gabazine treatment in ovo (Wilhelm and Wenner, 2008). It remained possible that interneurons experienced scaling and contributed to the homeostatic recovery of SNA in the first hours of gabazine treatment. However, following $6 \mathrm{~h}$ of gabazine treatment in ovo, we found no change in interneurons in AMPA mPSC amplitude (Fig. 7A) or decay kinetics (Extended Data Fig. 7-1). We would not have expected GABAergic scaling to contribute to the recovery of movements as we were blocking GABARs. Regardless, we did not see any change in GABA mPSC amplitude (Fig. $7 A$ ) or decay kinetics (Extended Data Fig. 7-1) in interneurons following a 6 -h gabazine treatment in ovo. The results show that neither AMPAergic nor GABAergic scaling in interneurons contributed to the homeostatic recovery of activity levels.

It was shown previously that scaling is not triggered in motoneurons after $12 \mathrm{~h}$ of gabazine treatment (Wilhelm and Wenner, 2008). We tested whether AMPAergic and GABAergic scaling was expressed in motoneurons following $6 \mathrm{~h}$ of gabazine treatment in ovo. We found no difference in AMPAergic or GABAergic mPSC amplitude (Fig. 7C) or decay kinetics (Extended Data Fig. 7-1) from 


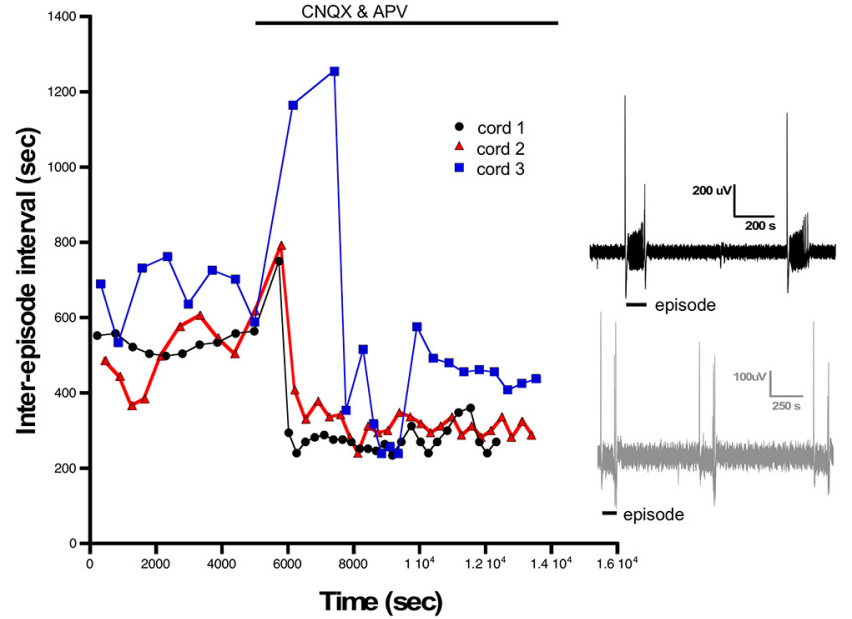

Figure 8. Episodes of SNA are delayed and then recover following glutamatergic blockade. The interval between episodes of SNA are plotted against elapsed time for three different cords before and following treatment with CNQX and APV (20 and $50 \mu \mathrm{m}$, respectively). Episode intervals are increased just after adding glutamate receptor antagonists but then recover to a higher rate. Inset shows example traces of SNA from a cord before (black) and after bath addition of CNQX/APV (gray). Traces were filtered from $0.1 \mathrm{~Hz}$ to $10 \mathrm{kHz}$.

controls. These findings showed that synaptic scaling of AMPAergic mPSCs in different spinal populations could not have contributed to the recovery of SNA or the movements it drives following GABAergic blockade. Finally, there was no compensatory increase in MPSC frequency in interneurons (Fig. 7B), or motoneurons (Fig. 7D). In fact, we found a significant reduction in GABAergic mPSC frequency.

\section{Recovery of embryonic movements following glutamatergic blockade is mediated by fast changes in RMP}

Previous work has demonstrated that a similar homeostatic recovery of embryonic movements was observed following either glutamatergic or GABAergic blockade (Wilhelm and Wenner, 2008). Movements recovered in around $12 \mathrm{~h}$, but after $12 \mathrm{~h}$ of glutamatergic blockade, no synaptic scaling or homeostatic changes in intrinsic excitability were observed. However, it is unknown whether changes in intrinsic excitability occur at earlier time points in the presence of glutamatergic antagonists. Therefore, we isolated spinal cords and applied CNQX $(20 \mu \mathrm{M}) / \mathrm{APV}$ $(50 \mu \mathrm{M})$ to the in vitro preparation and monitored the expression of SNA. We saw that glutamatergic blockade delayed the next episode of activity but then recovered to a slightly faster rate than before the drugs were added (Fig. 8). As reported previously (Chub and O'Donovan, 1998), the duration of the episodes of SNA was reduced following bath addition of CNQX/APV (Extended Data Fig. 8-1). We examined the compensatory changes in intrinsic excitability that might mediate the increased excitability of these cords. We assessed intrinsic excitability from 0 to 6 $\mathrm{h}$ of glutamate receptor blockade in the continued presence of the antagonists. We observed that motoneurons did indeed express reductions in threshold current from 2 to $6 \mathrm{~h}$ and a hyperpolarized threshold voltage at 4-6 $\mathrm{h}$ of drug application (Fig. 9B,C; Table 1). In addition, there was a significant depolarization of RMP (>10 mV) from 0 to $6 \mathrm{~h}$ accompanied by no change in input resistance from 0 to $4 \mathrm{~h}$ (Fig. 9D,E; Table 1). Similar changes were observed in interneurons following glutamatergic blockade, however the compensations in threshold voltage and RMP $(>15 \mathrm{mV})$ were even more dramatic, while threshold voltage was slightly hyperpolarized but this did not reach significance (Fig. 10; Table 1). The results suggest fast homeostatic changes in membrane potential significantly contribute to compensatory changes triggered by neurotransmitter receptor blockade. Together, the results focus our attention on homeostatic changes in RMP as contributors to the recovery of embryonic movements during either GABAergic or glutamatergic blockade.

\section{Discussion}

Homeostatic mechanisms such as synaptic scaling and changes in voltage-gated conductances are thought to be the main strategies that allow maintenance of activity levels. Here, we describe a new mechanism for homeostatic recovery using compensatory changes in RMP that occurs in the first hours of the perturbation.

\section{Homeostatic mechanisms and their contribution to the recovery of embryonic activity following neurotransmitter receptor blockade}

Synaptic scaling was not expressed at $6 \mathrm{~h}$ in motoneurons or interneurons (Fig. 7), and therefore, this form of homeostatic plasticity does not appear to be involved in the recovery of embryonic spinal activity, consistent with previous work (Wilhelm and Wenner, 2008). While scaling does not appear to mediate the recovery in the embryonic spinal cord, it appears to influence recovery of spiking activity in the cortex following in vivo sensory deprivation (Hengen et al., 2013; Glazewski et al., 2017; however, see Bridi et al., 2018).

Compensatory changes in homeostatic intrinsic excitability were observed following 6 and $12 \mathrm{~h}$ of in vivo GABAergic blockade. Significant reductions in threshold current were observed in both motoneurons and interneurons. This appears to be largely due to a hyperpolarization of the threshold voltage. On the other hand, compensatory changes in RMP were not observed, with one exception (interneurons following a 6-h gabazine treatment). Therefore, GABAR blockade in vivo triggers clear compensatory changes in threshold voltage at both 6 and $12 \mathrm{~h}$ of treatment that can be observed in the isolated cord no longer in the presence of the GABAergic antagonist.

These mechanisms were different when the cord was treated with GABAergic or glutamatergic receptor antagonists in vitro, where the drugs remained in place as we made measurements of cellular excitability. We observed some changes in threshold voltage in motoneurons and interneurons, but it was clear that reductions in threshold current were, in this case, largely due to significant depolarizations in RMP (>10 mV), at $0-2,2-4$, and 
A

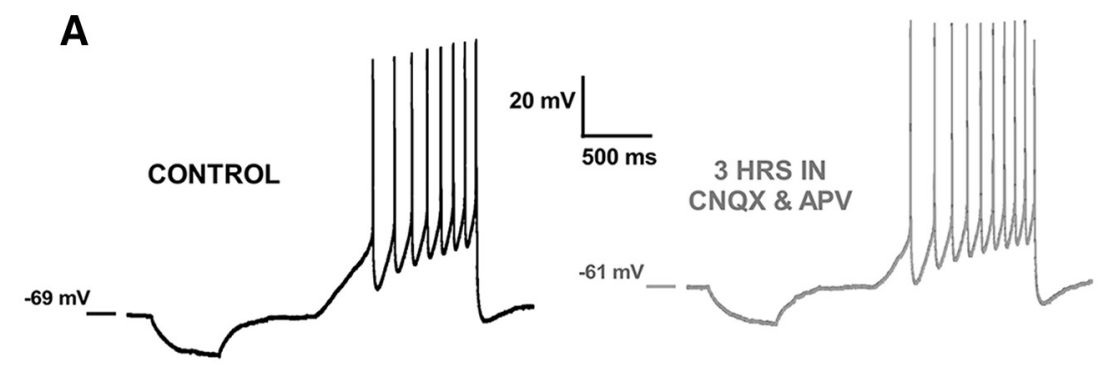

B

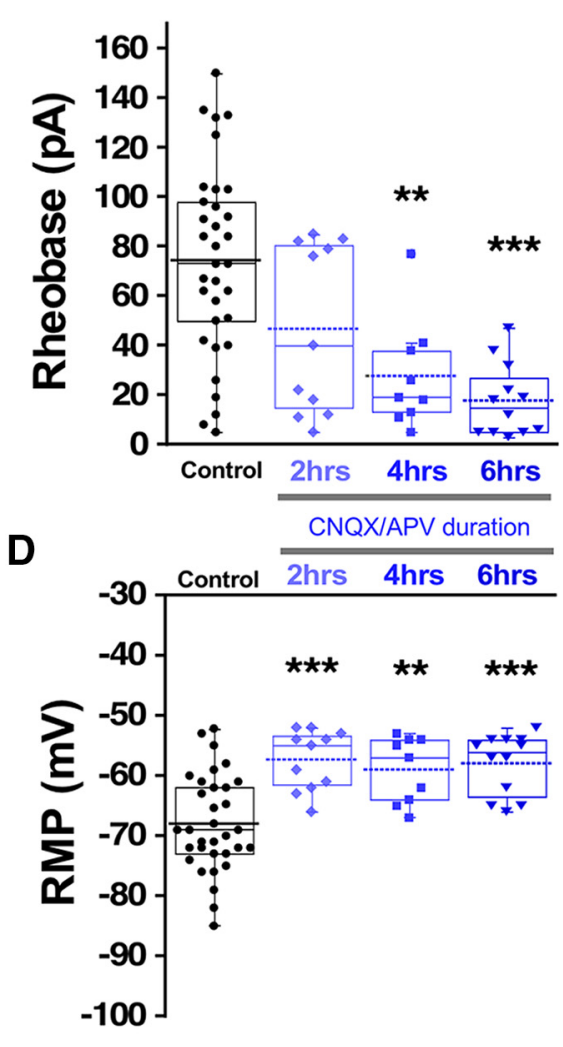

C

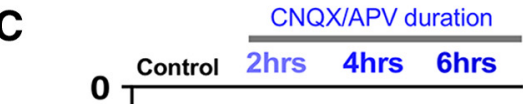

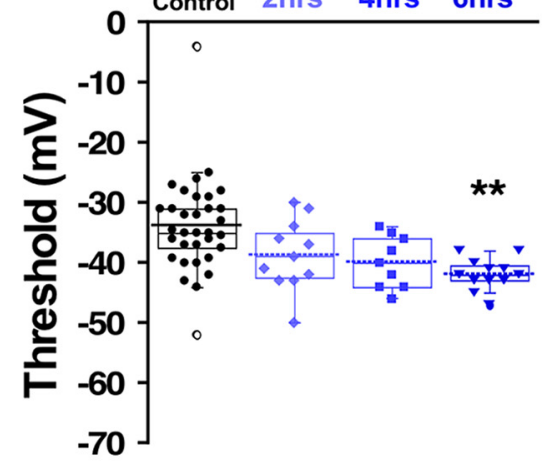

E

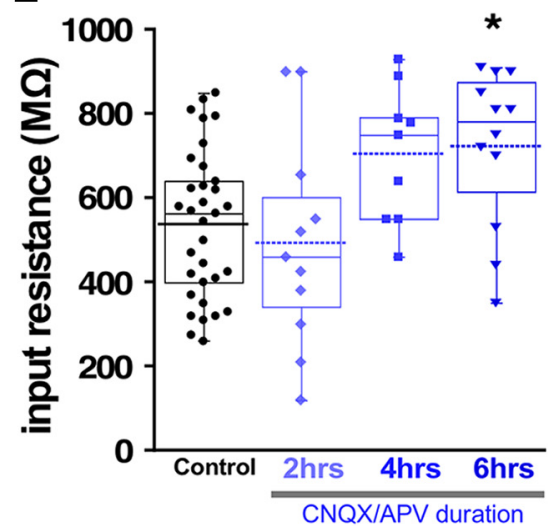

Figure 9. Motoneuron excitability increased following in vitro glutamatergic blockade. Motoneuron excitability was measured in isolated spinal cords using a ramp protocol from 0 to $200 \mathrm{pA}$ in $1.2 \mathrm{~s}$ to assess rheobase current and voltage threshold in the absence (control, 33 cells; 12 cords) or in the continuous presence of $10 \mu \mathrm{M}$ CNQX and $50 \mu \mathrm{M}$ APV at three different blockade periods: 0-2 $\mathrm{h}$ (11 cells, four cords), 2-4 h (eight cells, three cords), and 4-6 h (12 cells, four cords). Representative traces of motoneuron firing in control and after $3 \mathrm{~h}$ of continuous CNQX and APV in the bath $(\boldsymbol{A})$. Box and dot plots showing quartile distribution and individual values for of the rheobase $(\boldsymbol{B})$, threshold $(\boldsymbol{C})$, RMP $(\boldsymbol{D})$, and input resistance $(\boldsymbol{E})$ in isolated spinal cord motoneurons. For all plots, the continuous line represents the median and the dotted line represent the mean of the sample; $* p<0.05, * * p<0.01, * * * p<0.001$, ANOVA with Bonferroni post hoc test.

4-6 $\mathrm{h}$ of GABAergic or glutamatergic blockade in both motoneurons and interneurons. The recovery of embryonic movements following GABAergic and glutamatergic blockade were temporally very similar, although the mechanisms appeared to be distinct as compensatory changes in threshold current were not previously observed following a 12-h glutamatergic blockade in ovo (Wilhelm et al., 2009). This, therefore, focuses our attention on the fast homeostatic changes in RMP as a critical mechanism of homeostatic recovery of SNA in this developing circuitry.
The spinal interneurons were patched blindly, and so this population will represent a diverse one of many cell classes (Ritter et al., 1999). Therefore, in cases where we did not see a change in the measured parameter, the variability of the populations could contribute to this. Similarly, we did not distinguish among motoneurons projecting to different muscles, and so again this could contribute to variability. Importantly, no matter what kind of interneuron (GABAergic or glutamatergic) or motoneuron (femorotibialis or tibialis anterior) that we recorded from, the change in RMP was a universally observed feature. 
A

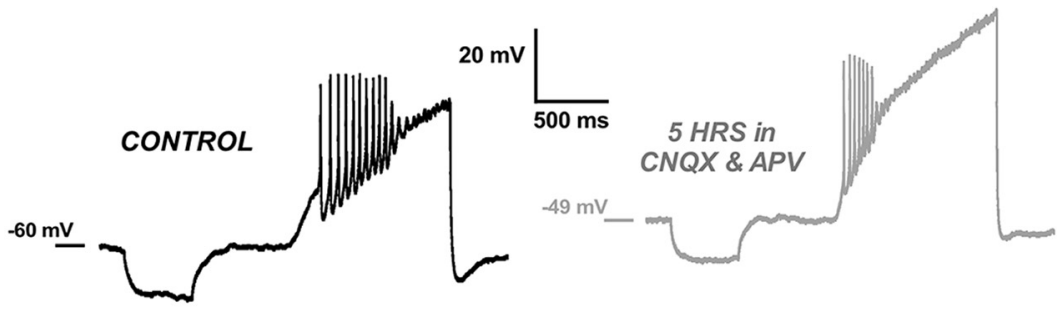

B

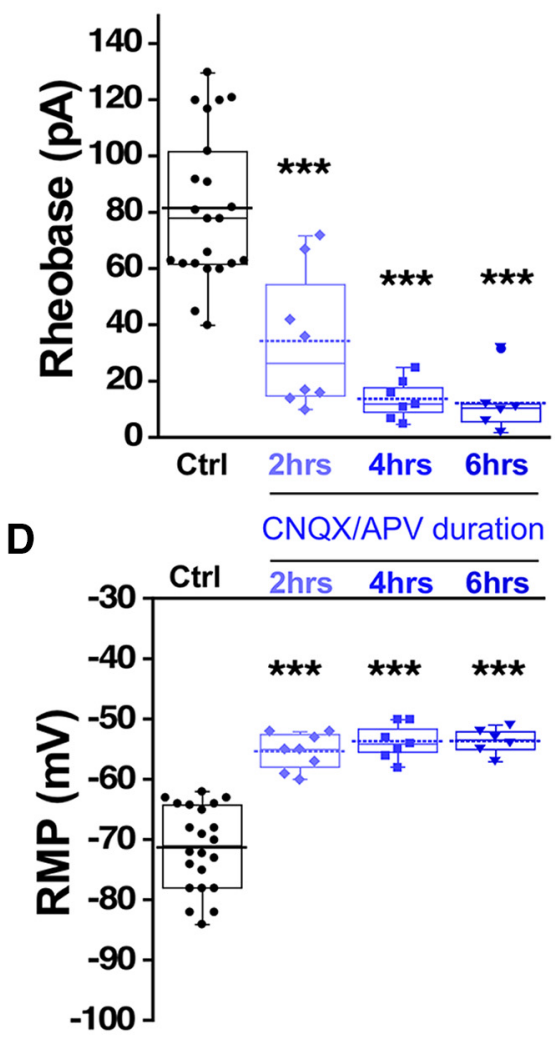

C

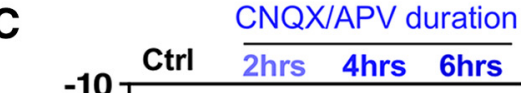

$E$

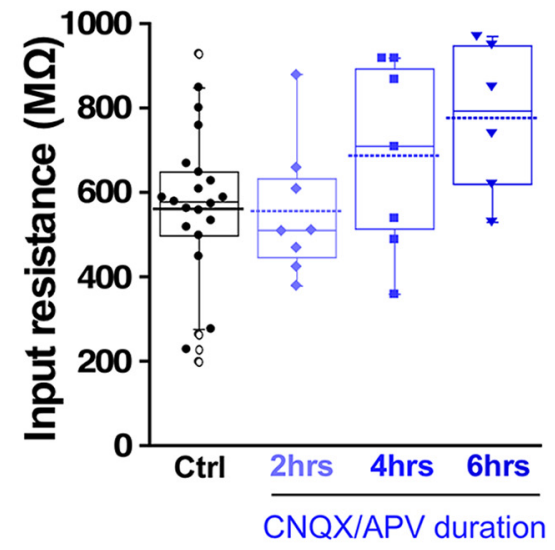

Figure 10. Interneuron excitability increased following in vitro glutamatergic blockade. Interneuron excitability was measured in isolated spinal cords with the same protocol used for motoneurons to calculate rheobase current and voltage threshold in controls without drugs (22 cells, eight cords, these are the same values as in Fig. 4 control interneurons) or in the continuous presence of $10 \mu \mathrm{M}$ CNQX and $50 \mu \mathrm{M}$ APV at three different blockade periods: 0-2 h (eight cells, three cords), 2-4 h (seven cells, three cords), and 4-6 h (six cells, three cords). $\boldsymbol{A}$, Representative traces of interneuron firing in control with no drugs and after $5 \mathrm{~h}$ of continuous $\mathrm{CNQX}$ and APV in the bath. Box and dot plots showing quartile distribution and individual values of rheobase (B), threshold (C), RMP $(\boldsymbol{D})$, and input resistance $(\boldsymbol{E})$ in isolated spinal cord. For all plots, the continuous line represents the median and the dotted line represent the mean of the sample. Sample size is indicated as (interneurons/chick embryos) in all plots; $* * * p<0.001$, ANOVA with Bonferroni post hoc test.

Further, it is becoming clear that variability is a biological reality as functionally equivalent cells and circuits can achieve their common behaviors using highly different strategies or parameter space solutions (distinct constellations of synaptic and voltage-gated conductances; Marder et al., 2015).

\section{Homeostatic perturbations and RMP}

No changes in RMP were reported in two of the earliest studies on homeostatic plasticity where different strategies were used to chronically block spiking for days (TTX, CNQX, or cell isolation), in rat cortical cultures (Turrigiano et al., 1998) or the stomatogastric neurons of the lobster (Turrigiano et al., 1994). Since these early studies, several other homeostatic experiments have been performed where spiking or neurotransmission were chronically blocked to trigger homeostatic synaptic or intrinsic plasticity and no changes in RMP were observed. These studies have been conducted using various perturbations (TTX, TTX/APV, CNQX, NBQX, gabazine, bicuculline, cell isolation) in rat 
cortical cultures (Turrigiano et al., 1998), mouse cortical cultures (Bülow et al., 2019), and in the embryonic spinal cord of the chick embryo in vivo (Gonzalez-Islas and Wenner, 2006; Wilhelm and Wenner, 2008; Wilhelm et al., 2009). On the other hand, none of these studies followed the RMP before and immediately after the perturbation as we have done in the current study. Therefore, changes in RMP may have occurred in these previous studies but over the duration and/or after removal of the perturbation no change was detected. An exception to this was described following a strong perturbation (two-week exposure to $15 \mathrm{~mm} \mathrm{KCl}$ ), where a homeostatic hyperpolarization of RMP was observed in cultured hippocampal neurons (O'Leary et al., 2010).

\section{Conductances that contribute to the RMP}

Several different ion channels exhibit activation at subthreshold potentials and thus contribute to setting the RMP including multiple kinds of $\mathrm{K}^{+}$channels (la, Ikir, lleak; Coetzee et al., 1999; Plant et al., 2019), hyperpolarization-activated cationic channels (Ih; Robinson and Siegelbaum, 2003; Biel et al., 2009), low-threshold calcium channels (Perez-Reyes, 2003), persistent sodium currents (NaPIC; Crill, 1996; Waxman et al., 2002), and leak sodium channels (NALCN; Lu et al., 2007; Ren, 2011). In addition, ongoing synaptic conductances can also influence the RMP (Mody and Pearce, 2004; Chuang and Reddy, 2018). Previous work has shown that blocking GABARs by direct application of a GABA receptor antagonist onto a chick embryo spinal cord preparation causes an acute hyperpolarization in spinal neurons that can be as large as $10 \mathrm{mV}$, suggesting a significant tonic GABAergic depolarizing current (Chub and O'Donovan, 2001). The effect of acute application of GABAergic antagonist onto the cord (Chub and O'Donovan, 2001) is in the opposite direction (hyperpolarizing) compared with the current studies finding that bath application of gabazine leads to a depolarization of RMP in the first hours of drug exposure. The current study is the only one we are aware of that follows RMP before and throughout the first hours of the perturbation and may explain why this form of homeostatic intrinsic plasticity has not been previously reported.

\section{Mechanisms of early homeostatic changes following neurotransmitter receptor blockade}

What is a potential trigger for these homeostatic changes in RMP? It has been shown previously that homeostatic synaptic scaling is triggered following $48 \mathrm{~h}$ block of GABAergic transmission (Wilhelm and Wenner, 2008) and compensatory changes in voltage-gated ion channel conductances by $12 \mathrm{~h}$ of GABAR block (Wilhelm et al., 2009). In fact, merely altering GABAR activation due to spontaneous release of GABA vesicles can fully trigger synaptic scaling (Garcia-Bereguiain et al., 2016). However, compensatory changes in RMP were not so reliant on GABAR activation. Fast changes in RMP were not triggered by altering the frequency of spontaneous vesicle-mediated GABAR activation (Fig. 6). Further, these changes can also be triggered by reduced glutamatergic receptor activation where GABAR activation is intact. Therefore, the most straightforward explanation for the trigger of homeostatic changes in RMP would be the reduction in network activity caused by blocking either glutamatergic or GABAergic receptors.

A commonly described mechanism underlying a change in RMP involves a change in some resting channel conductance (e.g., $\mathrm{K}^{+}$channels), however we did not detect a change in input resistance, making this possibility less likely. A potentially more plausible mechanism would involve a change in the function of the $\mathrm{Na}^{+} / \mathrm{K}^{+}$ATPase. Previous studies are consistent with this possibility. First, RMP of invertebrate neurons can be changed by an alteration of the electrogenic $\mathrm{Na}^{+} / \mathrm{K}^{+}$ATPase (Carpenter and Alving, 1968; Carpenter, 1973; Willis et al., 1974). Next, work in the spinal cord of Xenopus and neonatal mice, as well as in motoneurons of the fly larva, show that bursts of spiking activity expressed in these systems lead to an increase in intracellular $\mathrm{Na}^{+}$, that is necessary to activate an isoform of the $\mathrm{Na}^{+} / \mathrm{K}^{+}$ ATPase that is not active at baseline $\mathrm{Na}^{+}$levels. The $\mathrm{Na}^{+}-$ dependent activation of this $\mathrm{Na}^{+} / \mathrm{K}^{+}$ATPase produces a hyperpolarizing current due to the electrogenic nature of the pump that has been called an ultra-slow afterhyperpolarization (usAHP; Pulver and Griffith, 2010; Zhang and Sillar, 2012; Picton et al., 2017a,b). This hyperpolarizing current is maintained for up to a minute. SNA in the chick embryo spinal preparation experiences a very similar usAHP after episodes of SNA (O'Donovan, 1999; Chub and O'Donovan, 2001). Further, embryonic spinal neurons have very high $\mathrm{Na}^{+}$concentrations at baseline (Lindsly et al., 2017). Therefore, it is possible that $\mathrm{Na}^{+}$levels constitutively activate this $\mathrm{Na}^{+} / \mathrm{K}^{+}$ATPase and when SNA is blocked for many minutes by glutamatergic or GABAergic antagonists, $\mathrm{Na}^{+}$levels eventually are reduced to a point that pump activity is minimized and the hyperpolarizing current abates, thus depolarizing the RMP.

Most of our results appear to suggest that the changes in RMP are expressed transiently while the antagonists are in place, and once washed off the RMP returns to pre-drug levels. This kind of temporary perturbation might not permanently change the developmental trajectory of spinal neurons or their network. However, if this initial fast homeostatic mechanism does not recover activity levels or is maintained for long periods, then other mechanisms may be triggered, which could alter the development of the spinal circuitry in a long-lasting manner. This may be the case following GABAergic blockade where compensatory changes in threshold voltage are triggered in vivo and in vitro. This is consistent with previous 12-h GABAergic blockade in vivo where threshold current is dramatically reduced by compensatory changes in voltage-gated $\mathrm{Na}^{+}$and $\mathrm{K}^{+}$channels (Wilhelm et al., 2009). Changes in protein levels of two of these previously implicated voltage-gated ion channels were observed at $12 \mathrm{~h}$, although not at $6 \mathrm{~h}$ of in vivo gabazine treatment (Fig. 5). In some cases, homeostatic changes in RMP may be sufficient and exist temporarily, but in other cases these additional mechanisms could be engaged to recover the activity.

\section{References}

Barry MJ, O'Donovan MJ (1987) The effects of excitatory amino acids and their antagonists on the generation of motor activity in the isolated chick spinal cord. Brain Res 433:271-276. 
Ben-Ari Y, Cherubini E, Corradetti R, Gaiarsa JL (1989) Giant synaptic potentials in immature rat $\mathrm{CA} 3$ hippocampal neurones. J Physiol 416:303-325.

Biel M, Wahl-Schott C, Michalakis S, Zong X (2009) Hyperpolarization-activated cation channels: from genes to function. Physiol Rev 89:847-885.

Blankenship AG, Feller MB (2010) Mechanisms underlying spontaneous patterned activity in developing neural circuits. Nat Rev Neurosci 11:18-29.

Bridi MCD, de Pasquale R, Lantz CL, Gu Y, Borrell A, Choi SY, He K, Tran T, Hong SZ, Dykman A, Lee HK, Quinlan EM, Kirkwood A (2018) Two distinct mechanisms for experience-dependent homeostasis. Nat Neurosci 21:843-850.

Bülow P, Murphy TJ, Bassell GJ, Wenner P (2019) Homeostatic intrinsic plasticity is functionally altered in $\mathrm{Fmr} 1 \mathrm{KO}$ cortical neurons. Cell Rep 26:1378-1388.e3.

Carpenter DO (1973) Electrogenic sodium pump and high specific resistance in nerve cell bodies of the squid. Science 179:1336-1338.

Carpenter DO, Alving BO (1968) A contribution of an electrogenic $\mathrm{Na}+$ pump to membrane potential in Aplysia neurons. J Gen Physiol 52:1-21.

Chuang SH, Reddy DS (2018) Genetic and molecular regulation of extrasynaptic GABA-A receptors in the brain: therapeutic insights for epilepsy. J Pharmacol Exp Ther 364:180-197.

Chub N, O'Donovan MJ (1998) Blockade and recovery of spontaneous rhythmic activity after application of neurotransmitter antagonists to spinal networks of the chick embryo. J Neurosci 18:294-306.

Chub N, O'Donovan MJ (2001) Post-episode depression of GABAergic transmission in spinal neurons of the chick embryo. J Neurophysiol 85:2166-2176.

Coetzee WA, Amarillo Y, Chiu J, Chow A, Lau D, McCormack T, Moreno H, Nadal MS, Ozaita A, Pountney D, Saganich M, VegaSaenz de Miera E, Rudy B (1999) Molecular diversity of K+ channels. Ann NY Acad Sci 868:233-285.

Crill WE (1996) Persistent sodium current in mammalian central neurons. Annu Rev Physiol 58:349-362.

Davis GW (2013) Homeostatic signaling and the stabilization of neural function. Neuron 80:718-728.

Desai NS, Cudmore RH, Nelson SB, Turrigiano GG (2002) Critical periods for experience-dependent synaptic scaling in visual cortex. Nat Neurosci 5:783-789.

Dryer L, Xu Z, Dryer SE (1998) Arachidonic acid-sensitive A-currents and multiple Kv4 transcripts are expressed in chick ciliary ganglion neurons. Brain Res 789:162-166.

Echegoyen J, Neu A, Graber KD, Soltesz I (2007) Homeostatic plasticity studied using in vivo hippocampal activity-blockade: synaptic scaling, intrinsic plasticity and age-dependence. PLoS One 2: e700.

Garcia-Bereguiain MA, Gonzalez-Islas C, Lindsly C, Wenner P (2016) Spontaneous release regulates synaptic scaling in the embryonic spinal network in vivo. J Neurosci 36:7268-7282.

Glazewski S, Greenhill S, Fox K (2017) Time-course and mechanisms of homeostatic plasticity in layers $2 / 3$ and 5 of the barrel cortex. Philos Trans R Soc Lond B Biol Sci 372:20160150.

Goel A, Jiang B, Xu LW, Song L, Kirkwood A, Lee HK (2006) Crossmodal regulation of synaptic AMPA receptors in primary sensory cortices by visual experience. Nat Neurosci 9:1001-1003.

Gonzalez-Islas C, Wenner P (2006) Spontaneous network activity in the embryonic spinal cord regulates AMPAergic and GABAergic synaptic strength. Neuron 49:563-575.

Gonzalez-Islas C, Garcia-Bereguiain MA, O'Flaherty B, Wenner P (2016) Tonic nicotinic transmission enhances spinal GABAergic presynaptic release and the frequency of spontaneous network activity. Dev Neurobiol 76:298-312.

Hall BK, Herring SW (1990) Paralysis and growth of the musculoskeletal system in the embryonic chick. J Morphol 206:45-56.

Hamburger V, Hamilton HL (1951) A series of normal stages in the development of the normal chick embryo. J Morphol 88:49-92.

Hanson MG, Landmesser LT (2004) Normal patterns of spontaneous activity are required for correct motor axon guidance and the expression of specific guidance molecules. Neuron 43:687701.

Hengen KB, Lambo ME, Van Hooser SD, Katz DB, Turrigiano GG (2013) Firing rate homeostasis in visual cortex of freely behaving rodents. Neuron 80:335-342.

Jarvis JC, Sutherland H, Mayne CN, Gilroy SJ, Salmons S (1996) Induction of a fast-oxidative phenotype by chronic muscle stimulation: mechanical and biochemical studies. Am J Physiol 270: C306-C312.

Knogler LD, Liao M, Drapeau P (2010) Synaptic scaling and the development of a motor network. J Neurosci 30:8871-8881.

Kuba H, Oichi Y, Ohmori H (2010) Presynaptic activity regulates $\mathrm{Na}$ $(+)$ channel distribution at the axon initial segment. Nature 465:1075-1078.

Kuba H, Adachi R, Ohmori H (2014) Activity-dependent and activityindependent development of the axon initial segment. J Neurosci 34:3443-3453.

Lindsly C, Gonzalez-Islas C, Wenner P (2017) Elevated intracellular $\mathrm{Na}(+)$ concentrations in developing spinal neurons. J Neurochem 140:755-765.

Lu B, Su Y, Das S, Liu J, Xia J, Ren D (2007) The neuronal channel NALCN contributes resting sodium permeability and is required for normal respiratory rhythm. Cell 129:371-383.

Marder E, Goaillard JM (2006) Variability, compensation and homeostasis in neuron and network function. Nat Rev Neurosci 7:563574.

Marder E, Goeritz ML, Otopalik AG (2015) Robust circuit rhythms in small circuits arise from variable circuit components and mechanisms. Curr Opin Neurobiol 31:156-163.

Mody I, Pearce RA (2004) Diversity of inhibitory neurotransmission through GABA(A) receptors. Trends Neurosci 27:569-575.

Neher E (1992) Correction for liquid junction potentials in patch clamp experiments. Methods Enzymol 207:123-131.

O'Donovan MJ (1999) The origin of spontaneous activity in developing networks of the vertebrate nervous system. Curr Opin Neurobiol 9:94-104.

O'Donovan MJ, Landmesser L (1987) The development of hindlimb motor activity studied in the isolated spinal cord of the chick embryo. J Neurosci 7:3256-3264.

O'Donovan MJ, Chub N, Wenner P (1998) Mechanisms of spontaneous activity in developing spinal networks. J Neurobiol 37:131145.

O'Leary T, van Rossum MCW, Wyllie DJA (2010) Homeostasis of intrinsic excitability in hippocampal neurones: dynamics and mechanism of the response to chronic depolarization. J Physiol 588:157-170.

Perez-Reyes E (2003) Molecular physiology of low-voltage-activated t-type calcium channels. Physiol Rev 83:117-161.

Persson M (1983) The role of movements in the development of sutural and diarthrodial joints tested by long-term paralysis of chick embryos. J Anat 137:591-599.

Picton LD, Zhang H, Sillar KT (2017a) Sodium pump regulation of locomotor control circuits. J Neurophysiol 118:1070-1081.

Picton LD, Nascimento F, Broadhead MJ, Sillar KT, Miles GB (2017b) Sodium pumps mediate activity-dependent changes in mammalian motor networks. J Neurosci 37:906-921.

Plant LD, Bayliss DA, Minor DL, CZzirjak G, Enyedi P, Lesage F, Sepulveda F, Golsdstein SA (2019) Two P domain potassium channels (version 2019.4) in the IUPHAR/BPS guide to pharmacology database. IUPHAR/BPS Guide Pharmacol. Available at https://www.guidetopharmacology.org/GRAC/FamilyIntroduction Forward? familyld $=79$.

Pulver SR, Griffith LC (2010) Spike integration and cellular memory in a rhythmic network from $\mathrm{Na}+/ \mathrm{K}+$ pump current dynamics. Nat Neurosci 13:53-59.

Ren D (2011) Sodium leak channels in neuronal excitability and rhythmic behaviors. Neuron 72:899-911.

Ritter A, Wenner P, Ho S, Whelan P, O'Donovan MJ (1999) Activity patterns and synaptic organization of ventrally located 
interneurons in the embryonic chick spinal cord. J Neurosci 19:3457-3471.

Rivera C, Voipio J, Payne JA, Ruusuvuori E, Lahtinen H, Lamsa K, Pirvola U, Saarma M, Kaila K (1999) The K+/Cl- co-transporter $\mathrm{KCC} 2$ renders GABA hyperpolarizing during neuronal maturation. Nature 397:251-255.

Robinson RB, Siegelbaum SA (2003) Hyperpolarization-activated cation currents: from molecules to physiological function. Annu Rev Physiol 65:453-480.

Roufa D, Martonosi AN (1981) Effect of curare on the development of chicken embryo skeletal muscle in ovo. Biochem Pharmacol 30:1501-1505.

Ruano-Gil D, Nardi-Vilardaga J, Tejedo-Mateu A (1978) Influence of extrinsic factors on the development of the articular system. Acta Anat (Basel) 101:36-44.

Toutant JP, Toutant MN, Renaud D, Le Douarin GH (1979) Enzymatic differentiation of muscle fibre types in embryonic latissimus dorsii of the chick: effects of spinal cord stimulation. Cell Differ 8:375382.

Turrigiano G (2011) Too many cooks? Intrinsic and synaptic homeostatic mechanisms in cortical circuit refinement. Annu Rev Neurosci 34:89-103.
Turrigiano G, Abbott LF, Marder E (1994) Activity-dependent changes in the intrinsic properties of cultured neurons. Science 264:974-977.

Turrigiano GG, Leslie KR, Desai NS, Rutherford LC, Nelson SB (1998) Activity-dependent scaling of quantal amplitude in neocortical neurons. Nature 391:892-896.

Waxman SG, Cummins TR, Black JA, Dib-Hajj S (2002) Diverse functions and dynamic expression of neuronal sodium channels. Novartis Found Symp 241:34-51, discussion 51-60.

Wilhelm JC, Wenner P (2008) GABAA transmission is a critical step in the process of triggering homeostatic increases in quantal amplitude. Proc Natl Acad Sci USA 105:11412-11417.

Wilhelm JC, Rich MM, Wenner P (2009) Compensatory changes in cellular excitability, not synaptic scaling, contribute to homeostatic recovery of embryonic network activity. Proc Natl Acad Sci USA 106:6760-6765.

Willis JA, Gaubatz GL, Carpenter DO (1974) The role of the electrogenic sodium pump in modulation of pacemaker discharge of Aplysia neurons. J Cell Physiol 84:463-472.

Zhang HY, Sillar KT (2012) Short-term memory of motor network performance via activity-dependent potentiation of $\mathrm{Na}+/ \mathrm{K}+$ pump function. Curr Biol 22:526-531. 